\title{
Research of Teaching Methods for Professional Training Based on Project Driven Teaching Practices
}

\author{
Da Xiao ${ }^{1,2} \&$ Yong Liu $^{1} \&$ Lujia Cao ${ }^{1} \&$ Shengli Liu ${ }^{1,2} \&$ Dongyue Yan $^{1,2}$ \\ ${ }^{1}$ ZhengZhou Information Science University, 450001, Zhengzhou, Henan, China \\ ${ }^{2}$ State Key Laboratory of Mathematical Engineering and Advanced Computing, 450001, Zhengzhou, Henan, \\ China
}

\begin{abstract}
For business-oriented type of short-term training courses of this new task of teaching and teaching needs, to carry out an in-depth analysis and research, detailed the demand characteristics of these new teaching curriculum, on this basis, based on the design of a project-driven teaching practices, the implementation process is given in detail all aspects of teaching practice, and the teaching process should have the conditions and problems likely to face in-depth analysis of short-term training courses for such business-oriented type of conduct has implementation of targeted teaching a useful exploration and try.
\end{abstract} KEYWORD: P roject-driven; Office training; Teaching methods; Practice;

\section{INTRODUCTION}

In the modern knowledge environment, faster update rate of knowledge requires the ability to work with the knowledge structure of different jobs for talent is increasing, and knowledge of professional divided in more and more details. so that each person after the formal institutions of learning, can grasp the depth of knowledge and knowledge is very limited. In the face of the reality of business needs, they often need a wide variety of short-term training courses to deepen existing knowledge system, expand the breadth of knowledge. Emergence of such new teaching job, the ultimate goal is to enhance the knowledge content participating in the training of students to optimize their knowledge structure. Core essence of this deep-seated that the task of teaching is to compensate for the current traditional teaching process defects and deficiencies. Therefore, when faced with these new teaching tasks to carry out the design process of teaching and teaching practice, must be with the current implementation of the traditional teaching process to distinguish .

In response to this reality, the paper carried out on the business- oriented approach to teaching the practice of short-term training courses of study, trying to find a suitable method of teaching the new curriculum, the specific implementation process of teaching content, teaching process design and teaching.

\section{COURSE REQUIREMENTS ANALYSIS}

In order to better respond to the new task of teaching this new formulation appears more targeted and better teaching methods and practice, it is necessary to conduct in-depth analysis of this new type of teaching tasks and curriculum needs, combing difference between this type of new teaching requirements and existing traditional teaching tasks, as well as some new features that have the task of teaching. Through in-depth analysis of the actual teaching process undertaken by business- oriented demand for short-term training courses, summarizes the characteristics of this type of program has the following three aspects:

(1) The course of business targeted

Currently this type of short-term training courses undertaken, its training purpose revolves around the specific business needs of various types of units or work requirements are offered a series of training courses. Required to perform the jobs of employees working in this field to master the key technology skills. Thus, this short-term training courses all around the business units are some real business requirements, functional requirements, and the skills needs of the teaching task undertaken. All around the teaching process should be carried out so that the needs of the target.

(2) Strong practicality course content

Short courses of this kind of business- oriented and traditional teaching process is very different. In the traditional teaching process, often give students basic knowledge and impart relevant theory, the 
particular field in question, based on the principles used, the method of theoretical deduction and elaborated in detail, trying to equip students with the in the core areas of the most basic questions, and finally, according to the specific requirements of how much time and degree level students, selective, there are primary and secondary students to impart some knowledge of the application of such technology. The starting point is a good idea, but in practice the use of the process, often due to students' level and ability to apply relevant theory and technology is limited, resulting in its possession can not use existing theory to solve practical work appears the variety of new situations and new problems, resulting in between theory and practice issues.

The business-oriented type of short-term training courses with the traditional teaching process the difference is very obvious. In the business -type short-term training courses on the theory and principles of contextual knowledge is often not reported, or in a very short time to be explained to the students, so the training course organized by all the lectures and teaching process are carried out in order to improve students' technical skills specific to the target, so that students can in a short period of time, some special skills to master and apply preestablished .

(3) timeliness strong curriculum

This type of training generally have relatively clear norms and modes of teaching tasks and objectives are relatively clear. However, there are some special skills training is often a chase with the most current methods and techniques, their training goal is to make a few new ways to master the new technology can be extended in a relatively short period of time to go inside more employees, so that more employees are able to master and apply these new methods and skills in the short term, therefore, the teaching process has a very strong timeliness.

\section{LAYOUT OF TEXT PROJECT-DRIVEN TEACHING METHODS PRACTICE}

In order to address this new teaching tasks, develop targeted implementation methods of teaching, after an in-depth analysis of this class of business -type short courses demand is proposed based on projectdriven teaching practices . The basic idea of this method is: choose a range of practical cases and some typical projects as the basis for the implementation of the teaching content, suitable for short-term training courses to develop teaching methods and teaching process on this basis, thus to promote student better grasp of the relevant learning content, to achieve the desired learning objectives. This process of study and practice of teaching practices, mainly to address the following three aspects:

(1)Select teaching content

Due to the project -driven teaching practices based on a series of typical cases and course design project as a blueprint, so what kind of cases and projects can be modeled as a basis for the implementation of teaching is teaching these courses in developing the implementation plan when the key issue to be resolved. So when selecting teaching content, you should first work on specific business units to carry out this type of business conduct indepth research in detail, on this basis, and then the selection of appropriate teaching content. Students use case studies and projects such as learning and practice blueprint reference environment, more close to the actual work process specific future facing work environment.

(2) Design of the teaching process

Design teaching process is to ensure that this type of business model to face short-term training courses throughout the process of teaching the key to achieve the desired objectives. To be able to do the kind of business -type short-term training courses, general education course is designed to be three aspects :

1) dividing the teaching content

Since the implementation of the curriculum in the teaching content is generally selected based on one or several of the classic cases or projects to drive this project in the form of students to complete a series of specific project goals as traction, to promote students' experience and understand the specific needs of the business unit for a particular business, mastering the operational work in a variety of skills. But the classic case of this kind are often larger or project, students take one up these projects as a basis for learning and practice modeled directly, often there will be difficult questions to get started in the beginning stages. Therefore, in carrying out such a project -driven teaching practices, the teaching of the selected content to refine into several sub- problems. In the process into sub-problems, we must follow three principles:

(I) ensure that all sub- division problems combined to cover the entire business training mission requirements, students are required to cover a variety of skills required to master .

(Ii) for each sub-problem when the division should have a certain degree of independence. To break a huge complexity of the problem, let the students for a few small issues to study, to reduce barriers to entry of the study.

(iii) Between for each sub-problem and should have a certain logic associated properties. Throughout the teaching process, we should take the whole project or case as traction, therefore, we must maintain a certain logic between the various subproblems . 
2) Build a phased implementation process

Phased implementation process has the advantage of allowing students to the complex problem into smaller problems to various stages of research and practice, and will not allow students to look at the face of large and complex projects, feel helpless, unable to start. Thus, in constructing a phased implementation process should ensure that the division is easy to practice various stages of implementation and enforcement, in practice this phased in gradually to students can analyze , problem-solving skills to boot, for students in the implementation process step by step in a phased manner to analyze and solve problems, and improve student motivation and achievement in the process of gradually advancing further encourage students to actively carry out follow-up research and practice.

In addition, during the implementation stages, in order for students to better understand and supervise the progress of the situation, the implementation phase of each instructor should also be conducive to the inspection and supervision. So the instructor can more clearly and accurately grasp the progress of the students found the problems in a timely manner to promote students to solve these problems, and ultimately to promote new learning phase .

3) build a barrier -style teaching process

The process of building barriers to teaching style refers to the instructional design process, students consciously learn to set up a series of obstacles , difficulties and problems students simulate business applications in the future that may be encountered during the exercise in which students practice obstacles ability to solve problems in the environment analysis .

In the process of constructing barriers to teaching, building on a variety of barriers is a critical issue . Obstacles to the construction process in general is to take the practical application scenarios simulated environment, introduction or design a series of practical problems that may arise, as well as some of the conditions during the project implementation can not meet, so that students find these problems in the process of project practice and the reverse inference based on the problems identified root causes of these problems, and ultimately achieve the ability to improve students' practical application of the goal .

(3) the implementation process of teaching

In the teaching process, the kind of teaching process-oriented business model of short-term training courses with the traditional teaching process is completely different. New teaching content and teaching more scientific and rational design process to make teaching practice also has its own characteristics:

First of all, in the actual work process, the implementation of a specific case or project but more often than not by a team working together to accomplish by one person, in the teaching practice, the students according to their ability, interest in learning, and to be engaged in future posts reasonable mix of demand characteristics and division, each team completed some practical tasks. In this grouping implementation process, both to train students how to work together to accomplish a specific project capacity through individual and team innovation, but also conducive to students' sense of community and collaboration capabilities. In addition, there is another important advantage that enables organizations to better teaching practice for teachers of students in each group carry out a check and supervise the progress of the project to address the teaching force and the number of students does not match the contradiction.

Second, focus on the time course implementation. In the business-oriented type of short-term training courses, because there is not much theory and abstract principle, is to develop more practical ability. The implementation process is often practical ability is relatively timeconsuming, and therefore short-term training courses in the conduct of such business- oriented, and generally take the relative concentration of teaching time, every time a relatively long time to implement the teaching mode. When the specific implementation of the general teaching is that each implementation is at least half a day, that is, four hours. Throughout the course of the implementation period, the time interval between two adjacent courses is generally not more than two days, this arrangement allows students to practice during the course of time to maintain good continuity.

Furthermore, the selection and the associated increase in supplementary staff. Although the process is carried out by groups of students to carry out teaching and implemented to some extent eased the pressure on teachers not enough manpower, but in practice the teaching process, students can still find the problem and the number of students in the learning process encountered in practice far beyond a teacher can not solve the problem of capacity. Therefore, it is necessary to add more teaching assistants to help students answering.

\section{PHOTOGRAPHS AND FIGURES TEACHING CONDITIONS AND IMPLEMENTATION ISSUES}

Business- oriented teaching practices in the shortterm training courses are designed in this paper is very different from traditional teaching methods and procedures in the design and selection of teaching content teaching process, therefore, in the implementation of the teaching, the need to prepare a prerequisite also with the traditional teaching process varied. In order to implement this new 
teaching process, this paper based on problems found during teaching practice and lessons learned, summarized the teaching aspects of the implementation of the following three preconditions:

(1) Select the appropriate conditions for the implementation of the project as a teaching

As a project -driven teaching practice, which is one of the prerequisites needed to implement the project as a condition suitable teaching implementation. This requires the creation of such institutions before the commencement of the course , you must have in-depth business issues related to research and understand and engaged in the same or related to this business process content. Group of researchers in the design of the teaching curriculum content has enough time for practice and project selection. High-quality teaching practice project is based on project -driven teaching practices important prerequisite and basis for the design of this article

(2) the ability of the training and upgrading of teachers

This new type of short-term training courses teaching practices, teacher's ability to put forward higher requirements. This design is based according to project-driven teaching practices, requiring teachers to carry out such programs before it has had the entire process involved in the curriculum -related businesses. The instructor can deeply understand and master the business type, business functions, as well as the requirements of its business practices covered in lectures and participate or assume a series of cases or practice associated with the project, has accumulated a wealth of practical experience. Then, based on their possession of these rich experience and deep understanding of the specific business, on this basis, combined with some of the advanced teaching methods and means, be careful of the entire teaching process, scientific and comprehensive design and analysis, to be able ultimately provide students with high-quality short-term training courses teaching practices.

This article from the study of such new course content and teaching methods, but also further confirms the face of this new teaching tasks carried out by the organization and teaching practices compared to traditional teaching practice, the teacher's ability to raise more high demand. In the course of preparation of the actual conduct of teaching in general, such programs need to hold teachers to spend more time to become familiar with the relevant business functions, operational characteristics, and in the case of an actual project to practice, experience and comprehend a variety of specific business content, design better teaching implementation. Meanwhile, the requirements for such courses taught teachers to spend more energy in the process of preparation of the course to study new teaching methods and means to actively maintain regular technical exchanges and the core business of teaching and research needs of each business unit.

\section{SUMMARY}

In order to better meet the needs of society and the market situation for talent in the conduct of such business-oriented type of short-term training courses implementation process must be carried out in-depth research and teaching methods. Employers need to be from the specific needs of individual talent, as well as the problems faced by the current depth analysis to identify the root causes of these problems and to develop a set of new teaching methods and teaching practice for students in the traditional ability teaching process does not reach or grasp able to get through this kind of make up and enhance the short-term training courses to meet the requirements of the employer.

\section{ACKNOWLEDGEMENTS}

The work supported by National ScienceTechnology Support Plan Project (2012BAH47B01); Supported by Science and Technology Innovation Team of Zhengzhou (10CXTD150); Supported by National Natural Science Foundation of China (61309007);

\section{REFERENCES}

[1] $\mathrm{Hu}$ Xinrong Yangtze University computer-based professional training mode task-driven teaching, 2008, (3) ,335-337.

[2] Lee Soo Ying, Wang Jianxin, Peng Jing. Matlab teaching task-driven teaching application. Electrical \& Electronic Education.2010, (4):41-43.

[3] Li Wei, Fang Fei. Task-driven teaching PROTEL99SE Teaching. Computer Knowledge and Technology, 2009, (4):1012-1013.

[4] Wang Kang. Australian Army Task Driven Approach and Its Implications for army training outside teaching. Military School of Economics, 2009, (1):91-93.

[5] Yan Gong Ming,Tao Sheng. " $4+1$ " four teaching content to build relationships when working in education Analysis. Military Higher Education Research, 2010, (4):45-47. 